\title{
Uso de Caracteres Fenológicos do Milho Como Indicadores do InÍCIO da INTERFerênCia Causada POR Plantas Daninhas ${ }^{1}$
}

\author{
Using Phenological Parameters to Identify the Onset of Weed Interference in Corn
}

\author{
SKÓRA NETO, F. ${ }^{2}$
}

\begin{abstract}
RESUMO - Plantas de milho podem apresentar variações fenotípicas conforme o ambiente a que estão sujeitas durante seu crescimento. O objetivo deste trabalho foi verificar se as alterações em caracteres fenológicos de plantas de milho, causadas pela presença de plantas daninhas, poderiam indicar o início da interferência e também o momento de início do seu controle. Os tratamentos referem-se a períodos de convivência do milho com as plantas daninhas - 0 a 7, 0 a 14,0 a 21,0 a 28, 0 a 35, 0 a 42, 0 a 49 e 0 a 56 dias após a emergência (DAE) do milho - e as testemunhas com e sem convivência durante todo o ciclo. A altura de plantas, o diâmetro do colmo e o número de folhas foram avaliados a cada sete dias, até $56 \mathrm{DAE}$ e no pendoamento (75 DAE). Avaliou-se também o rendimento de grãos de milho. O início da interferência das plantas daninhas nas três variáveis avaliadas e no rendimento de grãos foi simultâneo, a partir de $28 \mathrm{DAE}$. Os efeitos da interferência foram irreversíveis, não havendo recuperação das plantas após a retirada do estresse causado pela presença das plantas daninhas; portanto, o uso de caracteres fenológicos na indicação do início de controle não se mostrou apropriado.
\end{abstract}

Palavras-chave: Zea mays, competição, altura da planta, diâmetro do caule, número de folhas.

ABSTRACT - A field study was carried out to identify phenological parameters in corn indicative of the onset of weed interference and the moment to start weed control. The treatments consisted of different periods of weed/crop coexistence: 0 to 7, 0 to 14, 0 to 21, 0 to 28, 0 to 35, 0 to 42, 0 to 49 and 0 to 56 days after corn emergence (DAE), and checks with and without weeds. Plant height, stem diameter and leaf number were evaluated at every interval of seven days until 56 $D A E$ and at tasseling (75 DAE). Yield was also evaluated. The effect of weed on the three parameters evaluated and on yield reduction started simultaneously at 28 days after corn emergence. The effects on plants were irreversible. The plants were unable to recover after weed competition was removed; therefore, the use of phenological parameters as indicators of the start of weed control was shown to be inappropriate.

Key words: Zea mays, competition, plant height, stem diameter, leaf number.

\section{INTRODUÇÃO}

Estudos sobre competição de plantas daninhas com as culturas são efetuados sob duas principais abordagens. A primeira relaciona a intensidade competitiva das plantas daninhas com a redução no rendimento de grãos, a fim de verificar a necessidade ou não de alguma medida de controle. Os parâmetros mais utilizados para estabelecer essa relação são a densidade populacional (Cousens, 1985; Coble \& Mortensen, 1992; Voll et al., 2002), a área foliar (Vitta et al., 1994), a cobertura do solo (Passini, 2002) e a biomassa das plantas infestantes (Florez et al., 1999).

A segunda abordagem determina o período crítico de competição, ou seja, o período durante o ciclo da cultura em que as plantas daninhas

1 Recebido para publicação em 10.10.2002 e na forma revisada em 2.4.2003.

2 Pesquisador Científico, Ph.D., IAPAR - Instituto Agronômico do Paraná, Caixa Postal 129, 8400-1970, Ponta Grossa-PR, <skora@pr.gov.br>. 
devem ser controladas; nesse caso, os principais parâmetros utilizados em milho são o número de dias após a emergência da cultura (Kuva et al., 2001), a fase de desenvolvimento da cultura (Hall et al., 1992) ou as unidades térmicas (Bedmar et al., 1999).

Estabelecida a necessidade de controle, a época ideal para realizar essa intervenção é o final do Período Anterior à Interferência (PAI) (Pitelli, 1991), isto é, imediatamente antes do início da competição das plantas daninhas com a cultura. Esse período é, entretanto, variável, dependendo principalmente das espécies de plantas daninhas presentes, da época de emergência em relação à cultura, da densidade populacional, das práticas culturais e das condições edafoclimáticas (Blanco, 1982; Radosevich \& Holt, 1984). Por essa razão, torna-se difícil determinar o momento para o controle em uma situação específica de associação entre plantas daninhas e cultura por meio da extrapolação de outros resultados experimentais, utilizando-se parâmetros como dias ou estádio da cultura. Conseqüentemente, verifica-se que nos casos em que os herbicidas permitem maior flexibilidade de aplicação em relação ao estádio das plantas daninhas e da cultura, ou mesmo no caso de controle manual ou mecânico, a decisão do momento de iniciar o controle tem sido baseada na experiência do técnico ou agricultor.

O uso de parâmetros fenológicos ou fisiológicos da cultura que permitissem identificar com antecedência o início da competição poderia contribuir para decisões mais técnicas no controle das plantas daninhas.

Em milho, condições de estresse durante o período vegetativo afetam a produção de matéria seca das plantas, com reflexo no rendimento de grãos (Maas, 1993; Schild et al., 1999). No entanto, alguns estudos demonstram que as plantas de milho apresentam capacidade de recuperação após determinados níveis de desfolha nas fases iniciais de desenvolvimento (Piper \& Weiss, 1993; Hicks et al., 1977; Shapiro et al., 1986).

Dessa forma, procurou-se identificar, em plantas de milho, algum caractere fenológico relacionado à produção de matéria seca que pudesse indicar o início da interferência das plantas daninhas. Objetivando definir o momento ideal para realizar o controle, avaliouse também a capacidade de recuperação das plantas de milho quando retirado o estresse provocado pela presença das plantas daninhas.

\section{MATERIAL E MÉTODOS}

O experimento foi realizado em Ponta Grossa-PR, em Latossolo Vermelho-Escuro, em sistema de preparo do solo convencional com uma aração e duas gradagens. A semeadura do milho (cv. AG303) foi feita manualmente, com seis sementes por metro linear (emergência de 5,5 plantas), no espaçamento de $0,90 \mathrm{~m}$ entre linhas. A adubação utilizada foi de $300 \mathrm{~kg} \mathrm{ha}^{-1}$ de 4-30-10 na semeadura e $200 \mathrm{~kg} \mathrm{ha}{ }^{1}$ de sulfato de amônia aos 43 dias (milho com 10 folhas) após a emergência (DAE).

Os tratamentos referem-se a diferentes períodos de convivência da cultura com as plantas daninhas em intervalos de sete dias após a emergência - 0 a 7,0 a 14,0 a 21,0 a 28,0 a 35,0 a 42,0 a 49 e 0 a $56 \mathrm{DAE}$ - e a testemunhas com e sem convivência durante todo o ciclo. O controle das plantas daninhas foi feito por meio de capina.

As condições climáticas foram normais, sem ocorrência de estresse hídrico.

O delineamento experimental adotado foi em blocos casualizados com quatro repetições. As parcelas mediam 4,5 x 6,0 m (5 linhas de milho), sendo as avaliações realizadas em sua área útil (3 linhas centrais de 5,0 m).

A cada sete dias após a emergência do milho (até os $56 \mathrm{DAE}$ ) avaliou-se o número de plantas daninhas por metro quadrado por espécie ( 11 amostras de $0,09 \mathrm{~m}^{2}$ ), no tratamento testemunha com convivência durante todo o ciclo. A altura das plantas de milho (do solo ao colar da última folha totalmente desenvolvida), o diâmetro do colmo (ao nível do solo) e o número de folhas totalmente desenvolvidas foram avaliados a cada sete dias (até os $56 \mathrm{DAE}$ ) nas testemunhas com e sem convivência durante todo o ciclo. No pendoamento, essas três variáveis foram avaliadas em todos os tratamentos. Segundo Gomes \& Karasawa (1982), pendoamento é o estádio que se caracteriza pelo término do crescimento da planta, que neste experimento ocorreu aos 75 DAE. Nas avaliações utilizaram-se 10 plantas por parcela, 
escolhidas aleatoriamente. No final do ciclo (149 DAE) foi avaliado o rendimento de grãos de milho.

Os dados obtidos foram submetidos à análise de variância. As curvas de porcentagem de redução no rendimento e de porcentagem de redução nos parâmetros avaliados, em relação ao tratamento testemunha sem convivência durante todo o ciclo, foram ajustadas com a equação de Gompertz: $\mathrm{Y}=\mathrm{a}$. EXP (-EXP $(\mathrm{b}-\mathrm{c} \cdot \mathrm{X})$ ). As curvas de rendimento e dos parâmetros avaliados foram ajustadas com a equação de Boltzman (Kuva et al., 2000). Para comparar as médias dos tratamentos de períodos de convivência utilizou-se o teste de comparação múltipla (LSD protegido $5 \%$ ).

\section{RESULTADOS E DISCUSSÃO}

As plantas daninhas predominantes na área do ensaio foram capim-marmelada (Brachiaria plantaginea, BRAPL), capim-colchão (Digitaria horizontalis, DIGHO), poaia-branca (Richardia brasiliensis, RCHBR), picão-branco (Galinsoga parviflora GASPA) e erva-quente (Spermacoce latifolia, BOILF). A população máxima, 670 plantas $\mathrm{m}^{-2}$, foi obtida aos $14 \mathrm{DAE}$ do milho. Após esse período, devido à competição intra e interespecífica, houve declínio no número total de plantas daninhas por área. A densidade média geral foi de 491 plantas $\mathrm{m}^{-2}$. A poaia-branca, que foi a espécie dominante nos períodos iniciais de desenvolvimento da cultura (Figura 1), apresentou a maior redução populacional.

A interferência das plantas daninhas nos caracteres fenológicos do milho iniciou-se aos 28 DAE e tornou-se mais intensa à medida que aumentou o período de convivência. Observouse efeito semelhante sobre o rendimento de grãos, com redução da produtividade a partir dos 28 DAE. A partir desses resultados, inferese que tanto o diâmetro do caule (Figura 2) como a altura das plantas (Figura 3 ) e o número de folhas (Figura 4) podem ser utilizados como indicadores do início da interferência das plantas daninhas sobre a cultura do milho.

Como indicadora prática de início de competição, a altura de plantas foi a melhor variável entre os caracteres avaliados, por ser de fácil mensuração no campo e proporcionar melhor diferenciação entre os valores absolutos obtidos para as plantas mantidas com e sem efeito de competição. As variáveis número de folhas e diâmetro do caule apresentaram pequena diferença entre os valores obtidos para as plantas mantidas na presença e ausência de plantas daninhas, o que dificulta a detecção do início da interferência.

$\mathrm{Na}$ avaliação feita aos $75 \mathrm{DAE}$ (pendoamento) verificou-se que ainda persistia a redução no diâmetro (Figura 5), na altura das plantas (Figura 6) e no número de folhas (Figura 7), mostrando que os efeitos da interferência foram irreversíveis; portanto, o uso

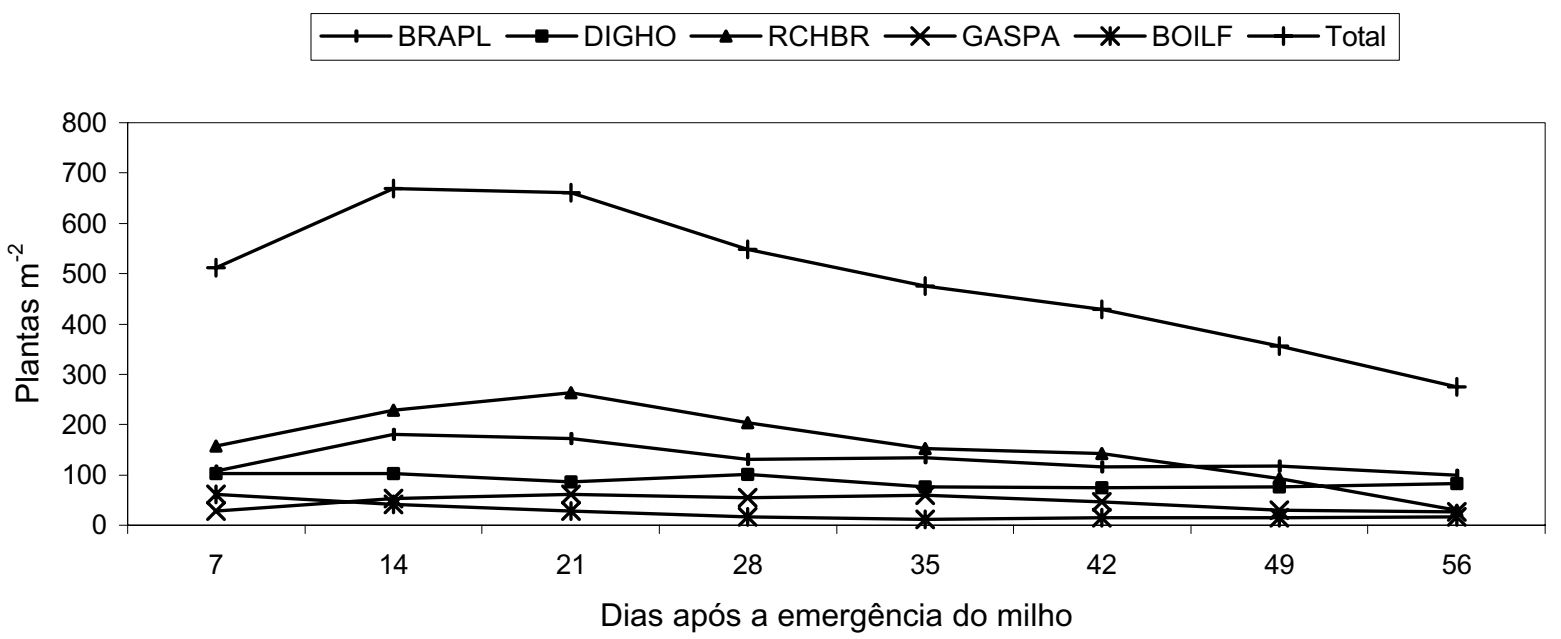

Figura 1 - Evolução da densidade das plantas daninhas até os 56 dias após a emergência do milho. 
dessas variáveis como indicadoras do início do controle não é adequado. O controle das plantas daninhas após a detecção do início da interferência não eliminou o seu efeito no rendimento de grãos (Figura 8), demonstrando que não houve recuperação das plantas de milho após a retirada do estresse a que estavam submetidas pela presença das plantas daninhas.

A falta de recuperação pode ser atribuída ao estádio de crescimento (a partir de $28 \mathrm{DAE}$ ou V7) no qual foi detectado o efeito da interferência, conforme demonstrado pelos trabalhos de Piper \& Weiss (1993), Hicks et al. (1977) e Shapiro et al. (1986), nos quais o desfolhamento do milho afetou significativamente o rendimento de grãos após o estádio V6. Além disso, no caso da interferência das plantas daninhas, diferentemente de desfolhamento, o estresse não é momentâneo e sim cumulativo e outras características fenológicas e fisiológicas são provavelmente afetadas durante a convivência, dificultando a recuperação das plantas.

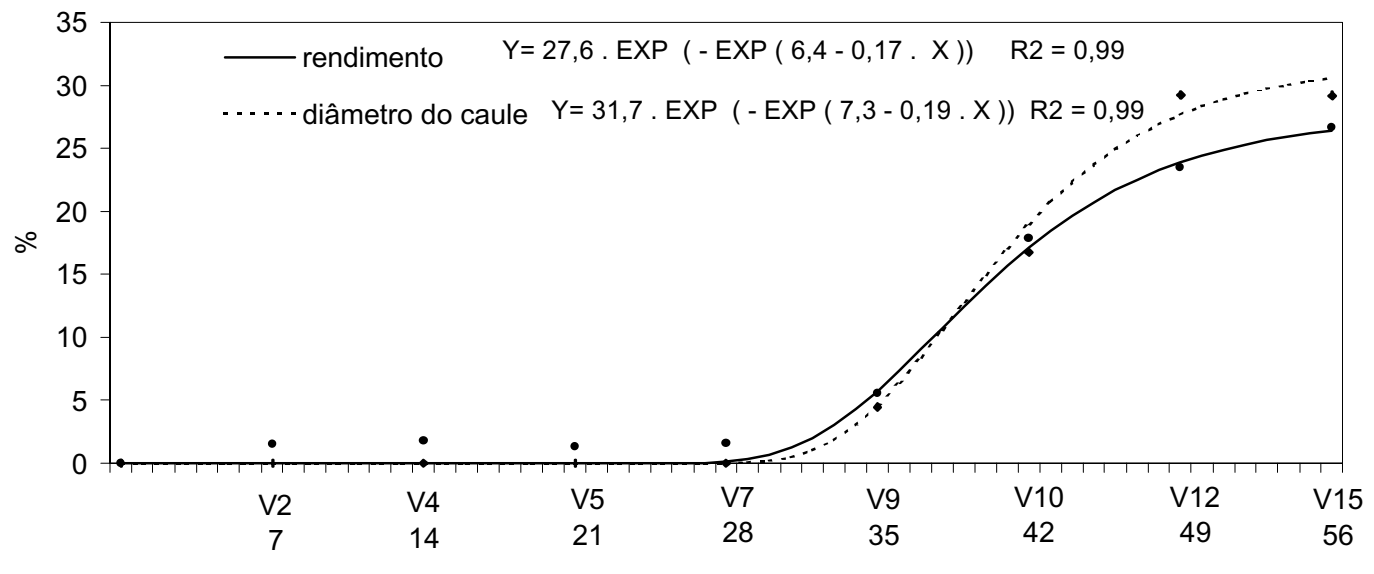

Estádio de crescimento e dias após a emergência do milho

Figura 2 - Porcentagem de redução no rendimento e no diâmetro do caule das plantas de milho que conviveram com as plantas daninhas, em relação às que não conviveram até 56 dias após a emergência.

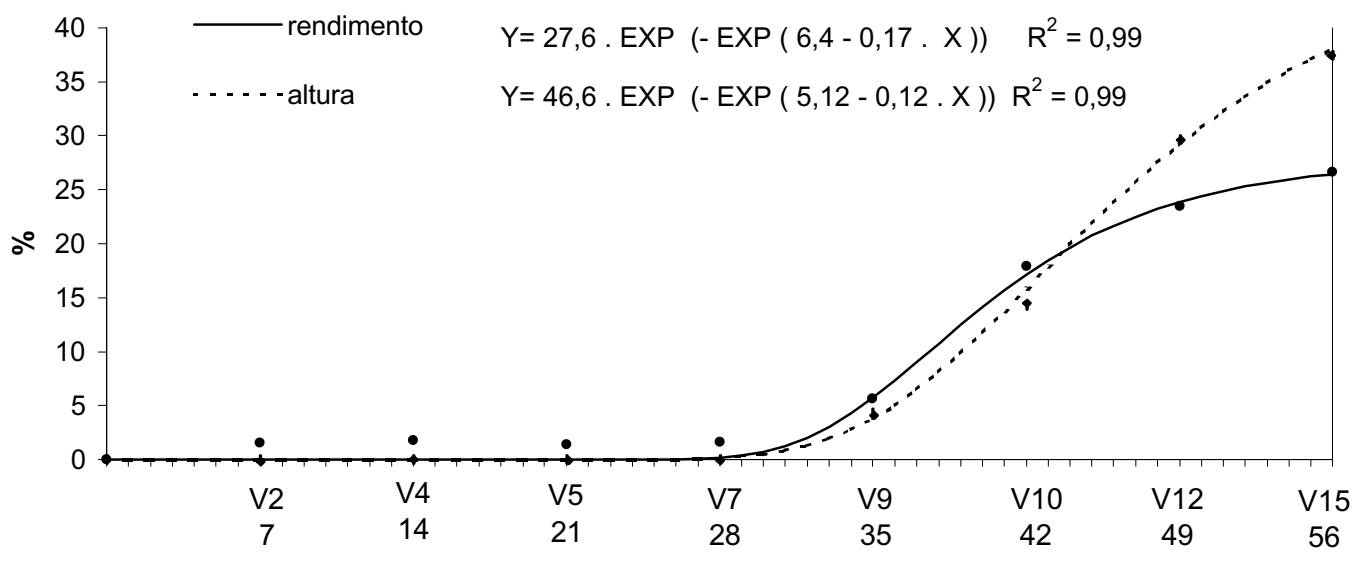

Estádio de crescimento e dias após a emergência do milho

Figura 3 - Porcentagem de redução no rendimento e na altura das plantas de milho que conviveram com as plantas daninhas, em relação às que não conviveram até 56 dias após a emergência. 


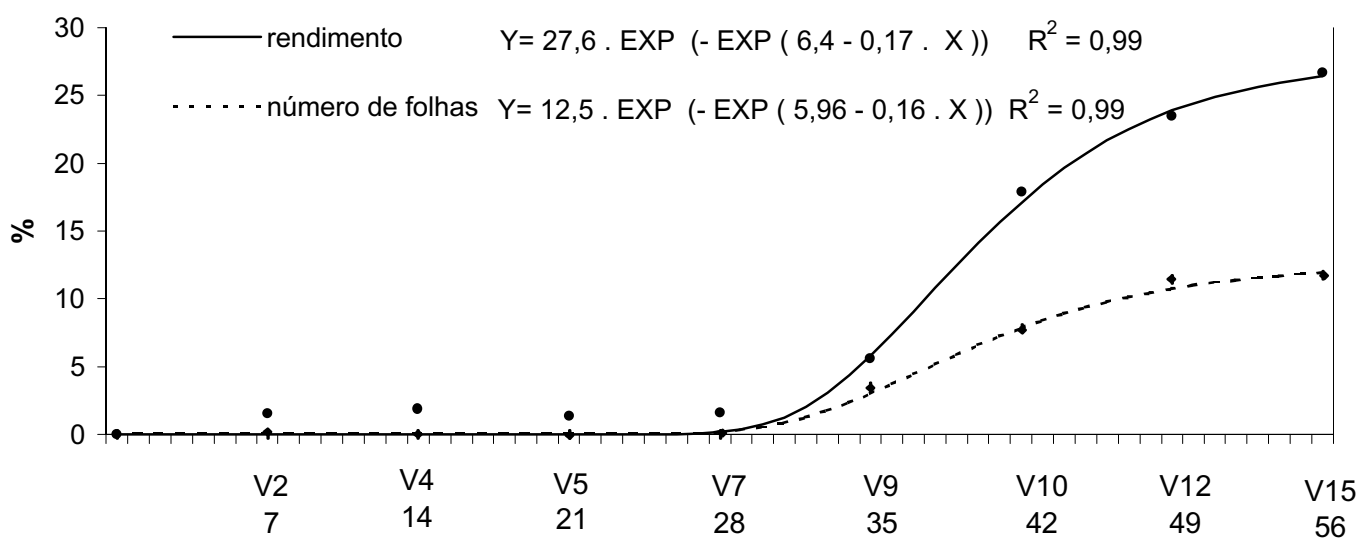

Estádio de crescimento e dias após a emergência do milho

Figura 4 - Porcentagem de redução no rendimento e no número de folhas das plantas de milho que conviveram com as plantas daninhas, em relação às que não conviveram até 56 dias após a emergência.

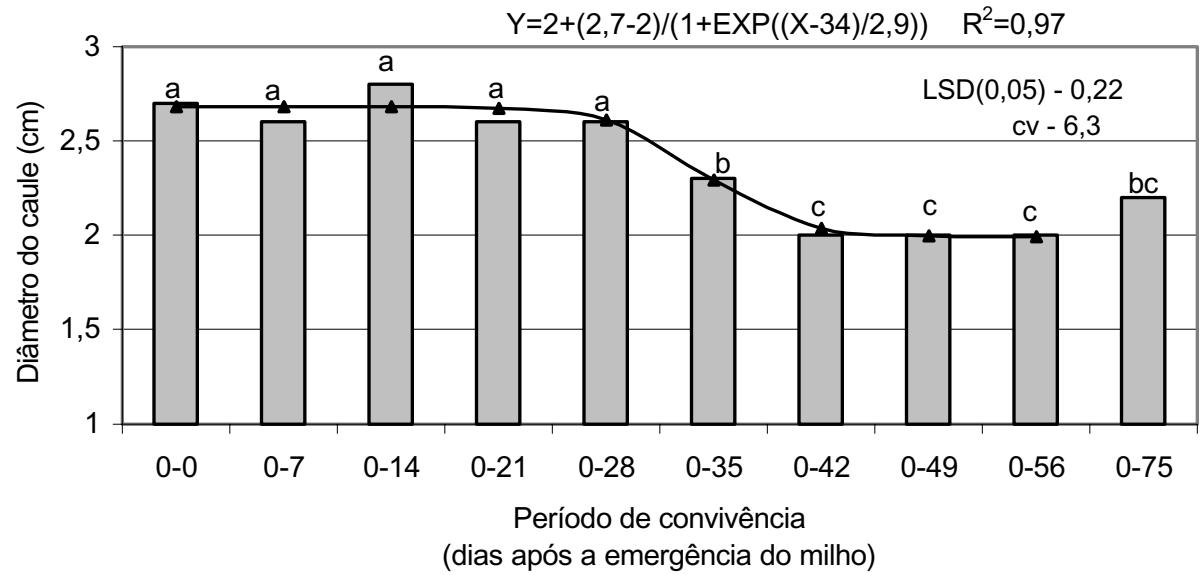

Figura 5 - Diâmetro do caule das plantas de milho no pendoamento (75 dias após a emergência), quando submetidas a diferentes períodos de convivência com as plantas daninhas.

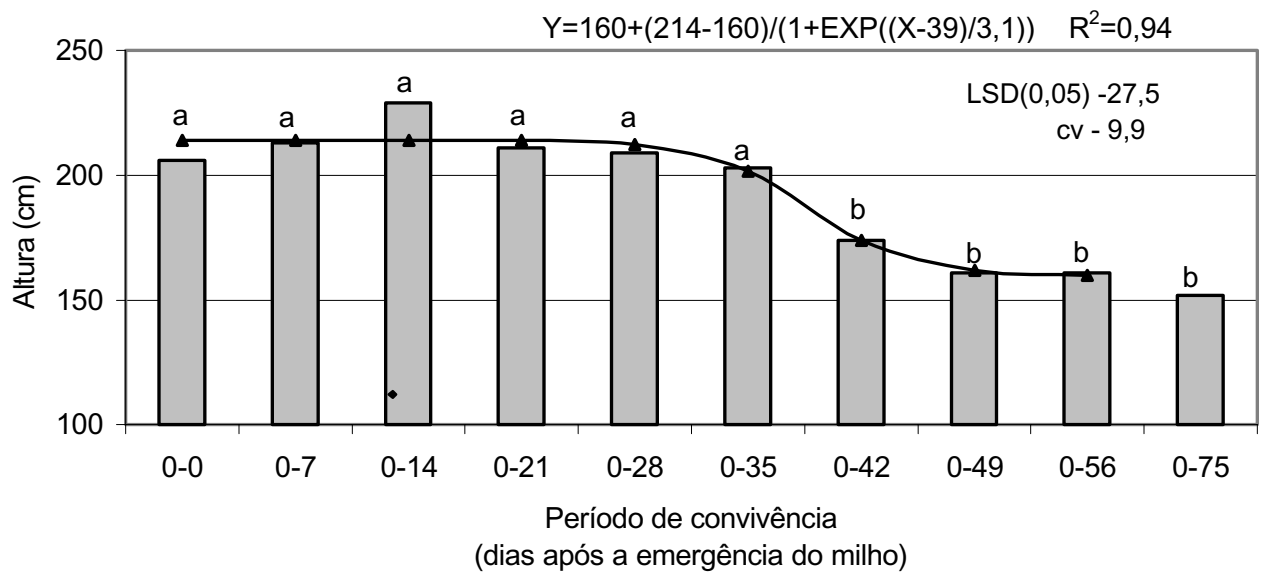

Figura 6 - Altura das plantas de milho no pendoamento (75 dias após a emergência), quando submetidas a diferentes períodos de convivência com as plantas daninhas. 


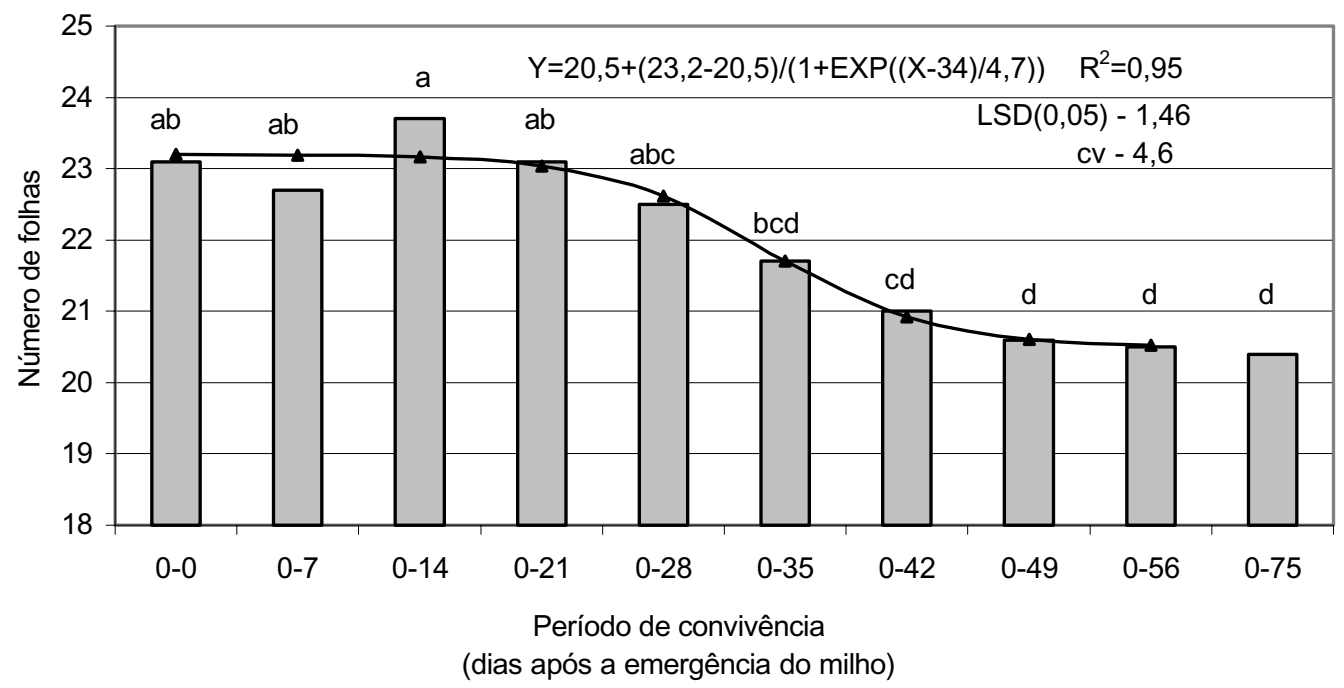

Figura 7 - Número de folhas das plantas de milho no pendoamento (75 dias após a emergência), quando submetidas a diferentes períodos de convivência com as plantas daninhas.

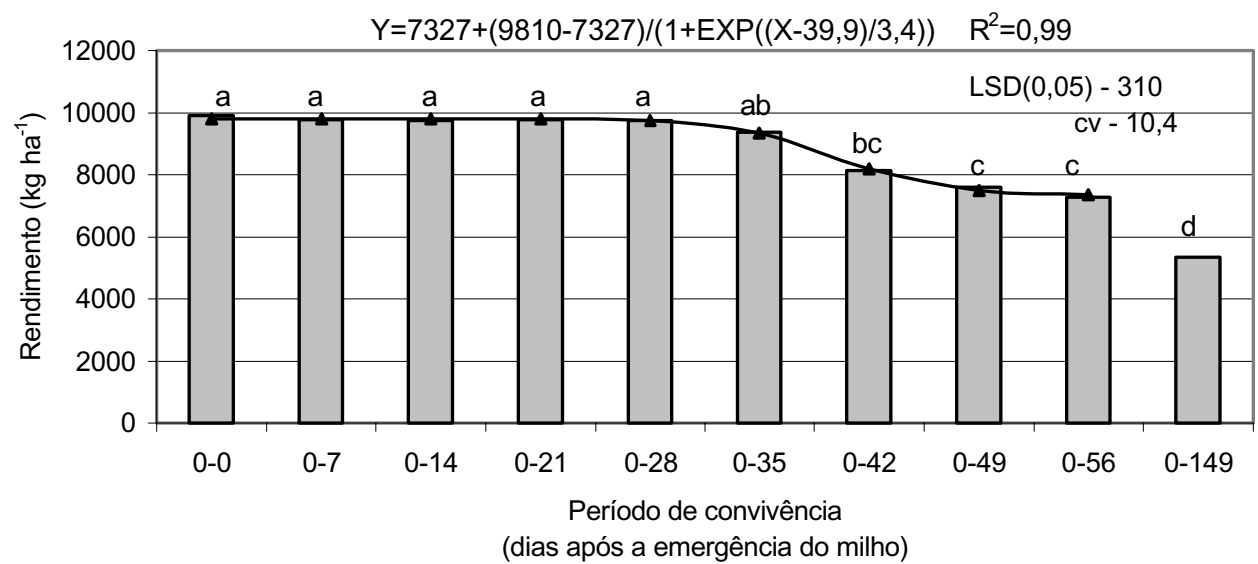

Figura 8 - Rendimento do milho, quando submetido a diferentes períodos de convivência com as plantas daninhas.

Dessa forma, embora os caracteres fenológicos avaliados possam indicar o início da interferência das plantas daninhas com o milho, eles não foram apropriados como indicadores do início do controle.

\section{LITERATURA CITADA}

BEDMAR, F.; MANETTI, P.; MONTERUBBIANESI, G. Determination of the critical period of weed control in corn using a thermal basis. Pesq. Agrop. Bras., v. 34, n. 2, p. 187-193, 1999.

BLANCO, H. G. Competição de plantas daninhas em culturas brasileiras. In: CREA. Controle integrado de plantas daninhas. São Paulo: 1982. p. 43-75.
COBLE, H. D.; MORTENSEN, D. A. The threshold concept and its application to weed science. Weed Technol., v. 6, n. 1, p. 191-195, 1992.

COUSENS, R. A simple model relating yield loss to weed density. Ann. Appl. Biol., v. 107, p. 239-252, 1985.

FLOREZ, J. A. et al. Predicting rice yield losses caused by multispecies weed competition. Agron. J., v. 91, p. 87-92, 1999.

GOMES, J.; KARAZAWA, M. Como a planta de milho se desenvolve. In: INSTITUTO AGRONÔMICO DO

PARANÁ - IAPAR. O milho no Paraná. Londrina: p. 3349. 1982 (Circular IAPAR, 29)

HALL, M. R.; SWANTON, C. J.; ANDERSON, G. W. The critical period of weed control in grain corn. Weed Sci., v. 40, n. 3, p. 441-447, 1992. 
HICKS, D. R.; NELSON, W. W.; FORD, J. H. Defoliation effects on corn hybridus adapted to the northern corn belt. Agron. J., v. 69, n. 3, p. 387-392, 1977.

KUVA, M. A. et al. Períodos de interferência das plantas daninhas na cultura da cana-de-açúcar. I - Tiririca. Planta Daninha, v. 18, n. 2, p. 241-251, 2000.

KUVA, M. A. et al. Períodos de interferência das plantas daninhas na cultura da cana-de-açúcar. II - Capimbraquiária (Brachiaria decumbens). Planta Daninha, v. 19, n. 3, p. 323-330, 2001

MAAS, S. J. Parameterized model of gramineous crop growth. I. Leaf area and dry mass simulation. Agron. J. , v. 85, n. 2, p. 348-353, 1993.

PASSINI, T. Competitividade e predição de perdas de rendimento da cultura de feijão quando em convivência com Brachiaria plantaginea. 2002. $130 \mathrm{f}$. Tese

(Doutorado em Agronomia-Fitotecnia) - Escola Superior de Agricultura "Luiz de Queiroz", Piracicaba, 2002.

PIPER, E. L.; WEISS, A. Defoliation during vegetative growth of corn: the shoot:root ratio and yield implications. Field Crops Res., v. 31, n. 1-2, p. 145-153, 1993.
PITELLI, R. Períodos de convivência possíveis e períodos críticos nas infestações de plantas daninhas em culturas anuais. Atual. Agríc., n. 6, p. 19-26, 1991.

RADOSEVICH, S. R.; HOLT, J. S. Weed ecology: implications for vegetation management. New York: John Wiley \& Sons, 1984. 265 p.

SCHILD, L. N. et al. Comportamento do milho em Planossolo sob condições de excesso hídrico. I. Desempenho agronômico. Agropec. Clima Temperado, v. 2, n. 1, p. 97-109, 1999.

SHAPIRO, C. A.; PETERSON, T. A.; FLOWERDAY, A. D. Yield loss due to simulated hail damage on corn: a comparison of actual and predicted values. Agron. J., v. 78, n. 4, p. 585-589, 1986.

VITTA, J. I.; SATORRE, E. H.; LEGUIZAMON, E. S. Using canopy attributes to evaluate competition between Sorghum halepense and soybean. Weed Res., v. 34, n. 2, p. 89-97, 1994.

VOLL, E. et al. Competição relativa de espécies de plantas daninhas com dois cultivares de soja. Planta Daninha, v. 20, n. 1, p. 17-24, 2002. 